\title{
Air pollution and mortality in New Zealand: cohort study
}

\author{
Simon Hales, ${ }^{1}$ Tony Blakely, ${ }^{2}$ Alistair Woodward ${ }^{3}$
}

${ }^{1}$ Department of Public Health, University of Otago, Wellington, New Zealand

¿University of Otago, Wellington, New Zealand ${ }^{3}$ University of Auckland, Auckland, New Zealand

\section{Correspondence to}

Dr Simon Hales, Department of Public Health, University of Otago, Wellington, 23a Mein Street, Wellington 6242, New Zealand;

simon.hales@otago.ac.nz

Statistics New Zealand Security Statement The New Zealand Census Mortality Study is a study of the relation between social factors and mortality in New Zealand, based on the integration of anonymised population census data from Statistics New Zealand and mortality data from the New Zealand Health Information Service. This project was approved by Statistics New Zealand as a data laboratory project under the Microdata Access Protocols in 1997. The datasets created by the integration process are covered by the Statistics Act and can be used for statistical purposes only. Only approved researchers who have signed Statistics New Zealand's declaration of secrecy can access the integrated data in the data laboratory. Access to the data used in this study was provided by Statistics New Zealand under conditions designed to give effect to the security and confidentiality provisions of the Statistics Act, 1975. The results presented in this study are the work of the author, not Statistics New Zealand. The authors take full responsibility for the paper and Statistics New Zealand will not be held accountable for any error or inaccurate findings.

Accepted 8 July 2010 Published Online First 21 October 2010

\section{UNIOCKAD}

This paper is freely available online under the BMJ Journals unlocked scheme, see http:// jech.bmi.com/site/about/ unlocked.xhtml

\section{ABSTRACT}

Background Few cohort studies of the health effects of urban air pollution have been published. There is evidence, most consistently in studies with individual measurement of social factors, that more deprived populations are particularly sensitive to air pollution effects.

Methods Records from the 1996 New Zealand census were anonymously and probabilistically linked to mortality data, creating a cohort study of the New Zealand population followed up for 3 years. There were 1.06 million adults living in urban areas for which data were available on all covariates. Estimates of exposure to air pollution (measured as particulate matter with an aerodynamic diameter less than $10 \mu \mathrm{m}, \mathrm{PM}_{10}$ ) were available for census area units from a previous land use regression study. Logistic regression analyses were conducted to investigate associations between causespecific mortality rates and average exposure to $\mathrm{PM}_{10}$ in urban areas, with control for confounding by age, sex, ethnicity, social deprivation, income, education, smoking history and ambient temperature.

Results The odds of all-cause mortality in adults laged $30-74$ years at census) increased by $7 \%$ per $10 \mu \mathrm{g} / \mathrm{m}^{3}$ increase in average $\mathrm{PM}_{10}$ exposure $(95 \% \mathrm{Cl} 3 \%$ to $10 \%)$ and $20 \%$ per $10 \mu \mathrm{g} / \mathrm{m}^{3}$ among Maori, but with wide $\mathrm{Cl}$ (7\% to $33 \%)$. Associations were stronger for respiratory and lung cancer deaths.

Conclusions An association of $\mathrm{PM}_{10}$ with mortality is reported in a country with relatively low levels of air pollution. The major limitation of the study is the probable misclassification of $\mathrm{PM}_{10}$ exposure. On balance, this means the strength of association was probably underestimated. The apparently greater association among Maori might be due to different levels of co-morbidity.

Anthropogenic air pollution is thought to cause a substantial global burden of disease, even if conservative assumptions are used for the analysis. ${ }^{1}$ Most epidemiological studies of air pollution effects use a time series design, in which day-to-day changes in morbidity or mortality (usually in a single city) are related to day-to-day changes in air pollution exposure. These studies have the advantage of controlling for time invariant (or slowly varying) confounding factors by design. Time series studies provide extensive and detailed evidence of short-term air pollution effects, but are not the best basis for public health policy on air pollution. ${ }^{2}$ This is because cohort studies suggest that long-term exposures have much greater public health impact than short-term exposures. Because it is difficult to estimate air pollution exposure for large populations over long periods, relatively few cohort studies have been reported and few such studies have been conducted outside north America and Europe. ${ }^{3-18}$
We report here the findings from a longitudinal study in New Zealand, based on the national census. In New Zealand, major sources of urban air pollution are home heating and motor vehicle emissions and levels of pollution are low by international standards. Typical annual average levels of particulate air pollution (particulate matter with an aerodynamic diameter less than $10 \mu \mathrm{m}, \mathrm{PM}_{10}$ ) at monitoring stations in the main urban centres are in the range $15-25 \mu \mathrm{g} / \mathrm{m}^{3}$. In this study, we analyse the spatial association between average $\mathrm{PM}_{10}$ exposure and mortality over the years 1996-9. We also investigate potential modification by social factors (age, sex, ethnicity, income, education and area level deprivation).

We hypothesise a priori that effects of $\mathrm{PM}_{10}$ on mortality will be stronger for cardiorespiratory causes of death than for all diseases, because these causes are most sensitive to air pollution effects.

\section{METHODS}

The New Zealand Census-Mortality Study is a population-wide cohort study, in which the cohort consists of the entire 1996 resident population ( $N=3732000)$ and the outcome of interest is mortality. For this analysis, records from the 1996 census were anonymously linked to 3 years of subsequent mortality data, creating a cohort study of the New Zealand population followed up for 3 years. ${ }^{19} 20$ In New Zealand, urban areas are defined as cities having a population of at least 30000 people; about half of the approximately 2000 census areas are classified as urban. Because the definition of 'urban areas' in New Zealand includes small towns and suburbs, many urban census areas have low levels of air pollution.

\section{Record linkage}

The method of record linkage has been described in detail elsewhere. ${ }^{19}$ Briefly, probabilistic record linkage is a process used to link two files of records, in which records in one file have a corresponding record in the other file. Records from the first file are compared with records from the second file in order to find 'matching' record pairs (ie, two records belonging to the same individual). Census and mortality records were linked using date of birth (day, month and year as separate matching variables), country of birth, sex, ethnicity and address of usual residence. (Geocoded addresses were the most discriminatory matching variable.) Linkage was restricted to individuals aged 74 years or below at the time of the census. The proportion of mortality records linked overall was $78 \%,{ }^{20}$ and varied by sex, age, ethnicity and the deprivation index. ${ }^{19}$ Weights were therefore applied to adjust for linkage bias, by strata of sex, age, 
ethnicity, deprivation, rurality and cause of death. ${ }^{21}$ For example, if 20 of 30 Maori men who died aged 45-64 years and living in moderately deprived (see below) rural areas of New Zealand were linked to a census record, each of the 20 linked records received a weight of $1.5(30 / 20)$. The estimated proportion of links being true links was $97 \%$.

\section{Air pollution exposure estimation}

Air pollution monitoring data are typically only available for a few sites and may not be representative of exposure in other areas. Detailed atmospheric dispersion modelling can be used to provide estimates of air pollution exposure for small areas, but these models are difficult to apply to large areas due to data and computer processing limitations. The method of air pollution exposure assessment has been described in detail elsewhere. ${ }^{22}$ Briefly, the approach to modelling long-term average $\mathrm{PM}_{10}$ was as follows. Atmospheric dispersion modelling results were available for one city (Christchurch, population 300 000). These data were assumed to be representative of the spatial pattern of annual average $\mathrm{PM}_{10}$ exposures for small areas (census area units) in Christchurch. ${ }^{23}$ Data on meteorological variables and indicators of air pollutant emissions for these areas were used as predictors of $\mathrm{PM}_{10}$ exposure in Christchurch, using regression models.

The predictors for the regression models were: census data on domestic heating; estimates of industrial emissions; and vehicle kilometres travelled within small areas. Because data for these predictor variables were available for all of New Zealand, we were able to extrapolate the empirical results for the Christchurch regression model to urban census area units throughout the country.

The resulting exposure estimates agreed well with multiyear averages of $\mathrm{PM}_{10}$ based on routine monitoring data for urban centres (1995-2001) $\left(\mathrm{N}=43 ; \mathrm{r}^{2}=0.87\right)$. While we acknowledge that there may be considerable exposure misclassification, we assume that the $\mathrm{PM}_{10}$ estimates are representative of long-term average spatial patterns of exposure during the 1990s.

Ideally, for analyses with the New Zealand Census Mortality Study data we would have used the continuous $\mathrm{PM}_{10}$ estimates for individual census areas. However, because the New Zealand Census Mortality Study data contain census information at unit record level, access to the data is restricted and additional data can only be added if confidentiality is not compromised as a result. Assigning continuous $\mathrm{PM}_{10}$ estimates at census area level would have permitted many census areas to be uniquely identified. In order to maintain confidentiality, it was necessary to aggregate the $\mathrm{PM}_{10}$ estimates into quintiles before they could be merged with the census data. Quintiles of exposure were calculated based on the estimates for individual census areas. For this purpose, we assigned a $\mathrm{PM}_{10}$ estimate of $0 \mu \mathrm{g} / \mathrm{m}^{3}$ to rural census areas where $\mathrm{PM}_{10}$ estimates were unavailable. The average $\mathrm{PM}_{10}$ level for all New Zealand census areas was $8.3 \mu \mathrm{g} /$ $\mathrm{m}^{3}\left(\mathrm{SD} 8.4 \mu \mathrm{g} / \mathrm{m}^{3}\right)$ and the cut-off values between $\mathrm{PM}_{10}$ quintiles were $0.0,0.5,12.5$ and $15.4 \mu \mathrm{g} / \mathrm{m}^{3}$.

Individuals were assigned to quintiles of $\mathrm{PM}_{10}$ exposure depending on their census area of residence on census night. In order to avoid bias affecting analyses in smaller rural areas due to migration to cities following the development of disease, we restricted the analyses to the urban population. This resulted in 1065645 observations $^{i}$ with complete data. Following restriction

'All counts were randomly rounded to a multiple of 3 in order to preserve confidentiality, as per Statistics New Zealand protocol. For this reason, subtotals may not match across categories. Note that regression analyses, however, were undertaken on actual unit record data. to the urban population, the lowest two quintiles of exposure had relatively few observations (table 1 ). For this reason, and given the small variation in PM levels between quintiles 1 and 2 , we combined the two lowest quintiles of $\mathrm{PM}_{10}$ to produce four categories in total. The estimated mean $\mathrm{PM}_{10}$ levels for these categories were $0.1,7,14$ and $19 \mu \mathrm{g} / \mathrm{m}^{3}$ (long-term averages).

Ethnicity and socioeconomic position are strong predictors of mortality in New Zealand, and potential confounders of the association of air pollution with mortality. We assigned each respondent to a mutually exclusive ethnic group using a prioritisation system commonly used in New Zealand: Maori, if any one of the responses was Maori; Pacific, if any one response was Pacific but not Maori; and the remainder non-Maori non-Pacific (mostly New Zealand European). Smoking status was reported in the census using the categories: never smoker, ex-smoker, or current smoker. ${ }^{24}$ Socioeconomic position was characterised as: total household income, with adjustment for the number of children and adults in the household to allow for economies of scale, log-transformed having first set all values of less than NZ $\$ 1000$ to equal NZ\$1000; ${ }^{20}$ highest educational qualification (higher than school, school, or none); and neighbourhood deprivation measured by the NZDep index (in quintiles). ${ }^{25}$ This index of deprivation within small geographical areas was calculated using census data on socioeconomic characteristics (eg, car access, tenure and receipt of benefits) at aggregations of approximately 100 people, and assigned to mortality data by use of address.

As climate is correlated with $\mathrm{PM}_{10}$, and associated with mortality (independently of $\mathrm{PM}_{10}$ ), temperature has the potential to confound air pollution effects. Therefore, we also included estimates of long-term average minimum temperature (in addition to the above sociodemographic factors) in the models, also in quintiles based on place of residence. These data were derived from an interpolated temperature surface. ${ }^{26}$ Mean values for the minimum temperature quintiles were $0.2,2,4,5$ and $7^{\circ} \mathrm{C}$.

Logistic regression analyses were conducted to investigate associations between all-cause and cause-specific mortality rates and average exposure to $\mathrm{PM}_{10}$, with control for confounding by age, sex, ethnicity, social deprivation, income, education, smoking history and average minimum temperature. As death is a rare outcome over 3 years for the age groups included in the analysis, logistic regression results differ very little from those from either Poisson or Cox proportional hazards modelling. Initial models incorporated $\mathrm{PM}_{10}$ categories as dummy variables, and given a reasonably linear dose-response, final models used the estimated mean $\mathrm{PM}_{10}$ for these four categories (see above). In order to facilitate comparison with overseas findings, we report results for adults aged $30-74$ years. In final models, age was included as a linear plus a squared term, and the income variable was natural-log transformed. All other covariates were included as dummy variables (table 2).

Any association of air pollution with mortality might be modified by social and environmental factors, due to different vulnerability or intensity of exposure to air pollution. We tested for interaction both by stratification and by inclusion of interaction terms.

Finally, we conducted a sensitivity analysis by restricting the dataset for analysis to those people who had lived in the same geographical unit at the 1991 census as they did at the time of exposure assignment (1996) in this cohort study. This restriction should reduce exposure misclassification by excluding those people who have not been exposed to the same level of $\mathrm{PM}_{10}$ for at least 5 years. 
Table 1 Summary data

\begin{tabular}{|c|c|c|c|c|c|c|c|c|c|}
\hline & \multicolumn{2}{|c|}{ Census counts } & \multicolumn{7}{|l|}{ Deaths* } \\
\hline & All & Complete data $\dagger$ & All causes & Natural causes $\ddagger$ & Cardiovascular & Respiratory & Lung cancer & Injury & Other \\
\hline \multicolumn{10}{|l|}{ Age (decade) } \\
\hline 30 & 443610 & 347772 & 1152 & 552 & 168 & 48 & 27 & 453 & 483 \\
\hline 40 & 375699 & 291885 & 1941 & 1482 & 567 & 156 & 96 & 294 & 927 \\
\hline 50 & 257274 & 199044 & 3645 & 3183 & 1155 & 474 & 309 & 186 & 1830 \\
\hline 60 & 199599 & 157185 & 7794 & 7056 & 2814 & 1410 & 759 & 186 & 3387 \\
\hline 70 & 88275 & 69750 & 6237 & 5664 & 2574 & 1125 & 495 & 111 & 2421 \\
\hline \multicolumn{10}{|l|}{ Sex } \\
\hline Male & 661314 & 515007 & 12468 & 10656 & 4881 & 1917 & 1044 & 903 & 4770 \\
\hline Female & 703137 & 550635 & 8301 & 7281 & 2397 & 1296 & 639 & 327 & 4281 \\
\hline \multicolumn{10}{|l|}{ Ethnicity } \\
\hline Maori & 121026 & 87825 & 2253 & 1908 & 861 & 414 & 243 & 180 & 801 \\
\hline Pacific & 59574 & 35916 & 771 & 651 & 315 & 84 & 54 & 42 & 327 \\
\hline European & 1183851 & 941904 & 17745 & 15378 & 6096 & 2715 & 1389 & 1011 & 7923 \\
\hline \multicolumn{10}{|c|}{ Income (tertiles) } \\
\hline Missing & 255492 & & & & & & & & \\
\hline Lower & 375462 & 356853 & 11973 & 10476 & 4410 & 2115 & 1038 & 537 & 4908 \\
\hline Middle & 363870 & 350490 & 5571 & 4779 & 1878 & 774 & 435 & 375 & 2547 \\
\hline Upper & 369627 & 358302 & 3225 & 2679 & 990 & 318 & 210 & 318 & 1596 \\
\hline \multicolumn{10}{|c|}{ NZDep (quintiles) } \\
\hline Missing & 768 & & & & & & & & \\
\hline \multirow[t]{4}{*}{ Rich } & 352656 & 289071 & 3918 & 3387 & 1278 & 477 & 252 & 234 & 1926 \\
\hline & 278199 & 225192 & 3729 & 3240 & 1254 & 531 & 291 & 204 & 1740 \\
\hline & 257613 & 204690 & 4014 & 3477 & 1389 & 612 & 333 & 237 & 1779 \\
\hline & 247107 & 189117 & 4473 & 3867 & 1608 & 774 & 405 & 267 & 1827 \\
\hline Poor & 228111 & 157572 & 4638 & 3963 & 1746 & 819 & 402 & 288 & 1779 \\
\hline \multicolumn{10}{|l|}{ Education } \\
\hline Missing & 66492 & & & & & & & & \\
\hline None & 443736 & 353280 & 10446 & 9150 & 3789 & 1860 & 981 & 480 & 4317 \\
\hline School & 344745 & 286479 & 4584 & 3915 & 1536 & 660 & 330 & 300 & 2091 \\
\hline Higher & 509478 & 425883 & 5742 & 4869 & 1953 & 693 & 372 & 450 & 2646 \\
\hline \multicolumn{10}{|l|}{ Smoking } \\
\hline Missing & 100926 & & & & & & & & \\
\hline Current & 283992 & 232995 & 5559 & 4713 & 1998 & 1317 & 789 & 450 & 1794 \\
\hline Past & 328548 & 283470 & 7812 & 6975 & 2784 & 1425 & 690 & 300 & 3300 \\
\hline Never & 650991 & 549180 & 7401 & 6246 & 2493 & 471 & 207 & 477 & 3957 \\
\hline \multicolumn{10}{|c|}{ Temperature $\left({ }^{\circ} \mathrm{C}\right)$} \\
\hline 0.2 & 168261 & 137571 & 3003 & 2625 & 1041 & 480 & 267 & 150 & 1335 \\
\hline 2 & 224265 & 176730 & 3849 & 3300 & 1329 & 648 & 315 & 234 & 1638 \\
\hline 3 & 249363 & 199971 & 4131 & 3576 & 1491 & 636 & 351 & 255 & 1752 \\
\hline 5 & 354780 & 275739 & 5172 & 4419 & 1809 & 807 & 414 & 330 & 2223 \\
\hline 7 & 367788 & 275634 & 4614 & 4014 & 1611 & 639 & 333 & 264 & 2100 \\
\hline \multicolumn{10}{|c|}{ Particulate $\left(\mu \mathrm{g} / \mathrm{m}^{3}\right)$} \\
\hline 0.1 & 72102 & 57213 & 999 & 861 & 348 & 135 & 69 & 51 & 462 \\
\hline 7 & 319914 & 251109 & 4665 & 3975 & 1659 & 702 & 375 & 312 & 1992 \\
\hline 14 & 506913 & 388134 & 7083 & 6132 & 2472 & 1050 & 549 & 417 & 3141 \\
\hline 19 & 465522 & 369189 & 8022 & 6969 & 2799 & 1323 & 693 & 444 & 3453 \\
\hline Totals & 1364451 & 1065645 & 20769 & 17937 & 7278 & 3210 & 1686 & 1224 & 9048 \\
\hline
\end{tabular}

*Weighted counts, for deaths occurring among the census respondents with complete data.

†The complete dataset is that used for final analyses in this paper.

$\ddagger$ All causes of death excluding accidents and injury.

\section{RESULTS}

When $\mathrm{PM}_{10}$ was modelled using dummy variables, there was an approximately linear increase in mortality with increasing average $\mathrm{PM}_{10}$ exposure (figure 1). Three models are shown: (1) adjusting for sex, age and ethnicity on all observations ( $N=1364454)$; (2) the same model, but restricted to observations with non-missing data on other covariates $(\mathrm{N}=1065645$; a test of any selection bias compared with model 1); (3) fully adjusted model ( $\mathrm{N}=1065645$; a test of possible confounding compared with model 2). There is no meaningful difference between models 1 and 2, suggesting no selection bias when restricting analyses to those with full data on covariates. Adjusting for potential confounders in model 3 attenuated the OR for all non-referent groups, although the relative differences between quintiles 3, 4 and 5 were not much reduced. That is, adjusting for confounders mostly closed the gap between the referent group and quintile 3 .

Considering the preferred model 3 , the OR increased monotonically and linearly with increasing $\mathrm{PM}_{10}$ level, and the $95 \% \mathrm{CI}$ for the two highest quintiles excluded 1.0. Given the approximately linear association of $\mathrm{PM}_{10}$ with mortality described above, subsequent models incorporated $\mathrm{PM}_{10}$ as a linear term, 
Table 2 Logistic regression model including all variables listed as independent variables (all deaths, all ethnicities: $\mathrm{N}=1065645$ )

\begin{tabular}{|c|c|c|c|}
\hline & \multirow[b]{2}{*}{$\mathbf{O R}$} & \multicolumn{2}{|c|}{$95 \% \mathrm{CI}$} \\
\hline & & lower & upper \\
\hline \multicolumn{4}{|l|}{ Particulate } \\
\hline $\mathrm{PM}_{10}\left(\mu \mathrm{g} / \mathrm{m}^{3}\right)$ & 1.007 & 1.003 & 1.010 \\
\hline \multicolumn{4}{|c|}{ Temperature quintile (base: lowest) } \\
\hline 2 & 0.967 & 0.915 & 1.022 \\
\hline 3 & 0.987 & 0.932 & 1.046 \\
\hline 4 & 0.957 & 0.908 & 1.010 \\
\hline 5 & 0.908 & 0.861 & 0.959 \\
\hline Age & 1.088 & 1.071 & 1.105 \\
\hline Age squared & 1.000 & 1.000 & 1.000 \\
\hline Natural log of income & 0.819 & 0.799 & 0.839 \\
\hline \multicolumn{4}{|l|}{ Sex (base: male) } \\
\hline Female & 0.598 & 0.579 & 0.618 \\
\hline \multicolumn{4}{|l|}{ Ethnicity (base: Māori) } \\
\hline Pacific & 0.813 & 0.731 & 0.905 \\
\hline European & 0.500 & 0.472 & 0.529 \\
\hline \multicolumn{4}{|c|}{ Deprivation quintile (base: least deprived) } \\
\hline 2 & 1.078 & 1.025 & 1.134 \\
\hline 3 & 1.173 & 1.116 & 1.234 \\
\hline 4 & 1.330 & 1.265 & 1.399 \\
\hline 5 & 1.548 & 1.469 & 1.632 \\
\hline \multicolumn{4}{|c|}{ Smoking (base: current smoker) } \\
\hline past & 0.706 & 0.677 & 0.736 \\
\hline never & 0.498 & 0.477 & 0.519 \\
\hline \multicolumn{4}{|l|}{ Education (base: none) } \\
\hline school & 0.933 & 0.895 & 0.971 \\
\hline higher & 0.860 & 0.828 & 0.894 \\
\hline
\end{tabular}

*Rounded; for logit form of model, constant $-6.528(-7.036$ to -6.020$)$.

using the average $\mathrm{PM}_{10}$ for each category) (tables 2 and 3 ). Table 2 shows the same model as in figure 1, except for the continuous treatment of $\mathrm{PM}_{10}$. The $\mathrm{OR}$ of 1.007 corresponds to a 1 unit increase in $\mathrm{PM}_{10}$, which equates to an increase of $7 \%(95 \% \mathrm{CI}$ $3 \%$ to $10 \%$ ) in the odds of all-cause mortality in adults (aged between age 30 and 74 years at census) per $10 \mu \mathrm{g} / \mathrm{m}^{3}$ increase in long-term average $\mathrm{PM}_{10}$ exposure.

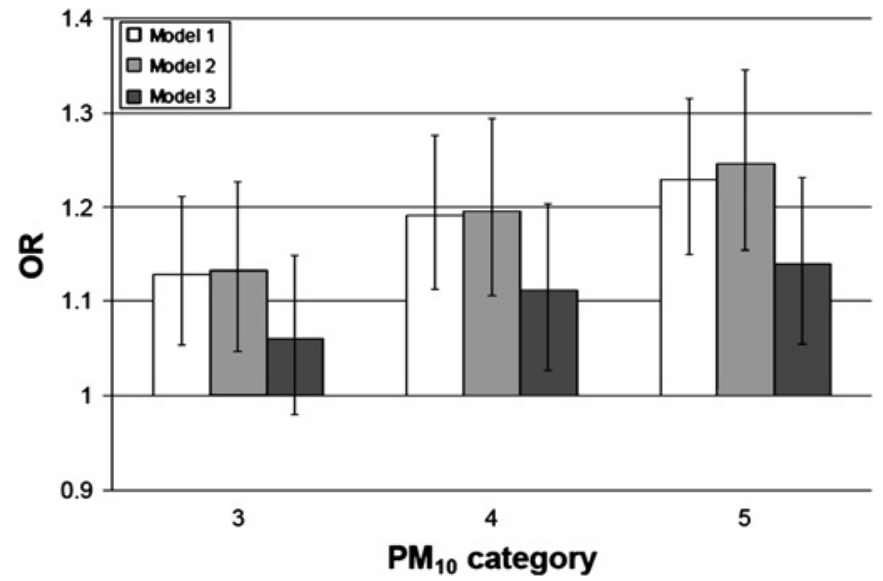

Figure $1 \mathrm{OR}$ and $95 \% \mathrm{Cl}$ of all-cause mortality for people living in the three non-referent $\mathrm{PM}_{10}$ categories, compared with quintiles 1 and 2 combined. Model is for sexes combined, restricted to adults aged $30-74$ years on census night, urban population, with covariates as follows: model 1: age, sex, ethnicity, all data, $\mathrm{N}=1364454$; model 2: age, sex, ethnicity, data with non-missing values for covariates in model $3, \mathrm{~N}=1065645$; model 3: age, sex, ethnicity, deprivation, income, education, smoking, temperature, $\mathrm{N}=1065645$.
Table 3 Findings by subgroups of ethnicity and cause of death (model 3 , fully adjusted)

\begin{tabular}{|c|c|c|c|c|}
\hline & $\mathbf{N}^{*}$ & $\begin{array}{l}\text { OR (per } 1 \\
\mu \mathrm{g} / \mathrm{m}^{3} \mathrm{PM}_{10} \text { ) }\end{array}$ & $\begin{array}{l}\text { Lower } \\
95 \% \mathrm{CI}\end{array}$ & $\begin{array}{l}\text { Upper } \\
95 \% \mathrm{Cl} \\
\end{array}$ \\
\hline \multicolumn{5}{|l|}{ Model } \\
\hline All deaths, all ethnicities & 1065645 & 1.007 & 1.003 & 1.010 \\
\hline $\begin{array}{l}\text { All deaths, living in the same } \\
\text { census area as for the } 1991 \text { census }\end{array}$ & 601401 & 1.008 & 1.004 & 1.011 \\
\hline $\begin{array}{l}\text { All natural causes, all ethnicities } \\
\text { (excludes accidents and injury) }\end{array}$ & 1063563 & 1.007 & 1.003 & 1.010 \\
\hline All natural causes, European & 940107 & 1.006 & 1.003 & 1.010 \\
\hline All natural causes, Maori & 87615 & 1.018 & 1.007 & 1.029 \\
\hline \multicolumn{5}{|l|}{$\begin{array}{l}\text { Analyses by specific cause of } \\
\text { death, based on ICD9 codes } †\end{array}$} \\
\hline Lung cancers (ICD 162) & 1050222 & 1.015 & 1.004 & 1.026 \\
\hline $\begin{array}{l}\text { Respiratory disease (ICD 162, } \\
470-478,490-519 \text { ) }\end{array}$ & 1051464 & 1.013 & 1.005 & 1.021 \\
\hline Cardiovascular disease (ICD 393-438) & 1054731 & 1.006 & 1.001 & 1.011 \\
\hline Accidents and injury (ICD 800-949) & 1049646 & 1.004 & 0.990 & 1.018 \\
\hline Other, includes unspecified $\neq$ & 1056288 & 1.005 & 1.001 & 1.010 \\
\hline
\end{tabular}

\footnotetext{
*Rounded.

†Note: Models included persons dying from the specified causes (coded 1) and people presumed alive at the end of follow-up (coded 0), but excluded persons dying from other causes. Respiratory disease includes lung cancers.

$\ddagger^{\prime} O$ ther' deaths are all those deaths (including unspecified) that are not included among lung cancer, respiratory, cardiovascular disease or accidents.

ICD, International Classification of Diseases.
}

We found stronger effects of $\mathrm{PM}_{10}$ among people who lived in the same census area in 1991 (at the time of the previous census), $8 \%$ ( $4 \%$ to $12 \%$ ) per $10 \mu \mathrm{g} / \mathrm{m}^{3}$ increase in $\mathrm{PM}_{10}$. By cause of death, the association was similar for all natural causes, $7 \%$ (3\% to $10 \%)$, but substantially stronger for respiratory deaths (including lung cancers), $14 \%$ (5\% to $23 \%$ ) and for lung cancers, $16 \%$ (4\% to $29 \%$ ). For cardiovascular disease, $6 \%$ (1\% to $12 \%)$ and for 'other and unspecified' causes of death, $5 \%$ (1\% to $10 \%$ ), the association was marginally significant; while for accidental deaths and injuries, the association was non-significant, $4 \%(-9 \%$ to $20 \%$ ) (table 3$)$.

Considering interaction with social variables, there was an apparently stronger association of $\mathrm{PM}_{10}$ with all-cause mortality among Maori, $20 \%$ (7\% to $33 \%$ ). However, the $95 \%$ CI for Europeans overlapped that for Maori, $7 \%$ (3\% to 10\%). A Wald test for interaction between ethnicity and $\mathrm{PM}_{10}$ was not significant $(p=0.12)$. There were no statistically significant interactions with age, sex, income, deprivation, educational status or average temperature. Mortality was lower among people living in warmer census areas, and the difference between the lowest and the highest quintile of annual average temperature was statistically significant.

\section{DISCUSSION}

Using linked mortality and census data, we report a significant positive association between estimated long-term exposure to air pollution $\left(\mathrm{PM}_{10}\right)$ and mortality in New Zealand urban areas. This setting includes approximately $75 \%$ of the New Zealand population, who are exposed to relatively low levels of $\mathrm{PM}_{10}$ compared with other countries.

Selection bias and confounding seem unlikely to explain our results. There is no evidence of selection bias (figure 1). The results persist after controlling for plausible confounders, including multiple measures of socioeconomic position and smoking. It seems unlikely that mismeasured or unknown confounders might explain the remaining association.

There is likely to be substantial misclassification of the air pollution exposure. Most of this misclassification was probably 
non-differential by mortality risk (meaning we have probably significantly underestimated the true strength of association). There is potential differential misclassification of $\mathrm{PM}_{10}$ by mortality risk in our study, because our assessment was based on modelling in one city using proxies, including domestic heating, estimates of industrial emissions and vehicle kilometres travelled within small areas. If these proxies are not such reliable predictors of $\mathrm{PM}_{10}$ in other cities, and are (say) correlated with socioeconomic position, then it may be that our $\mathrm{PM}_{10}$ estimates are also capturing aspects of socioeconomic exposure. However, the fact that an association remained after extensive control of socioeconomic factors, including individual level income and education, makes this an unlikely explanation of the results. The use of modelled estimates of $\mathrm{PM}_{10}$ exposure will tend to smooth the data and reduce the resulting CI. However, this should not affect the central effect estimates.

It is possible that less healthy people might migrate towards health services (or other service amenities) that happen to be in more polluted areas-a form of reverse causation or endogeneity. However, we think this is unlikely to be an important factor as New Zealand cities are relatively small (maximum 1.4 million), and most suburbs in New Zealand's main cities have relatively good access to hospitals.

The odds of all-cause mortality in adults (aged between 30 and 74 years at census) increased by $7 \%$ (95\% CI 3\% to 10\%) per $10 \mu \mathrm{g} / \mathrm{m}^{3}$ increase in average $\mathrm{PM}_{10}$ exposure. Our observations are consistent with an increasing number of studies of long-term exposure to particulate matter and mortality. ${ }^{3-10} 13-18$

The original US Six Cities Study reported an adjusted mortality rate ratio of 1.27 (95\% CI 1.08 to 1.48 ) for the most polluted compared with the least polluted city, corresponding to 18.2 and $46.5 \mu \mathrm{g} / \mathrm{m}^{3} \mathrm{PM}_{10}$, respectively ${ }^{3}$-equivalent to an increase in mortality of approximately $10 \%$ per $10 \mu \mathrm{g} / \mathrm{m}^{3} \mathrm{PM}_{10}$. In the US Nurses Health Study, there was a $16 \%$ (5\% to $28 \%$ ) increase in all-cause mortality per $10 \mu \mathrm{g} / \mathrm{m}^{3} \mathrm{PM}_{10}{ }^{14}$ It is not yet clear to what extent the heterogeneity in reported dose response in those studies is related to differences in the accuracy of exposure measurement, to differences in the toxicity of complex mixtures of pollutants at differing levels of exposure, and/or differences in the sensitivity of exposed populations.

The exposure measures in other studies are not directly comparable. Recent studies use the more specific measure $\mathrm{PM}_{2.5}$ (particulate matter with an aerodynamic diameter less than $2.5 \mu \mathrm{m}$ ) rather than $\mathrm{PM}_{10}$, whereas several European studies use black smoke or total suspended particulates as the exposure measure. The association between particulate air pollution exposure and mortality is usually found to be strongest for finer fractions, such that the dose response for $\mathrm{PM}_{2.5}$ is greater than for $\mathrm{PM}_{10}$, which in turn is greater than for total suspended particulates. An extended follow-up of the US Six Cities Study reported a $14 \%$ ( $6 \%$ to $22 \%$ ) increase in mortality per $10 \mu \mathrm{g} / \mathrm{m}^{3}$ $\mathrm{PM}_{2.5},{ }^{9}$ whereas the American Cancer Society Study reported 6\% (2\% to $11 \%$ ) and the Nurses Health Study $26 \%$ (2\% to $54 \%$ ), while coarse particulate matter exposure $\left(\mathrm{PM}_{10-2.5}\right)$ was not associated with an increase in mortality in that study. ${ }^{27} \mathrm{An}$ analysis based on electoral wards in the UK found a 1.3\% (1\% to $1.6 \%)$ increase in all-cause mortality per $10 \mu \mathrm{g} / \mathrm{m}^{3}$ increase in black smoke. ${ }^{10}$ In 18 regions in France, the PAARC study reported a $7 \%$ (3\% to $10 \%)$ increase per $10 \mu \mathrm{g} / \mathrm{m}^{3}$ increase in black smoke and a $5 \%$ (2\% to $8 \%$ ) increase for total suspended particulates. ${ }^{7}$ In The Netherlands, there was a $5 \%(0 \%$ to $10 \%)$ increase in mortality per $10 \mu \mathrm{g} / \mathrm{m}^{3}$ increase in black smoke.

Our study assessed the association of $\mathrm{PM}_{10}$ and mortality over 3 years. In the US Nurses Health Study, mortality was most strongly associated with average $\mathrm{PM}_{10}$ exposures in the 24 months before death. In the UK, the association, although weak, was stronger for exposure in the 4 years before death. However, a re-analysis of the American Cancer Society Study found no clear effect of exposure period. ${ }^{17}$

A priori, we hypothesised that the association of $\mathrm{PM}_{10}$ with mortality in our study would be stronger for a cohort restricted to those census respondents who lived in the same census area at the time of the 1991 census. We also hypothesised that the association of $\mathrm{PM}_{10}$ with mortality would be stronger for cardiorespiratory deaths. Our results were consistent with these a priori hypotheses, strengthening the ability to make causal inference.

There is some evidence, most consistently in studies with individual measurements of social factors, that more deprived populations are particularly sensitive to air pollution

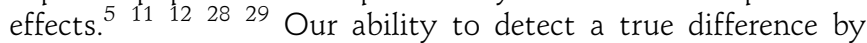
ethnicity in sensitivity to air pollution was limited by the relatively small Maori population. Although not significant, the difference in our central effect estimates for European and Maori was substantial: $7 \%$ versus $20 \%$. The reasons for this difference, if real, are not clear. This might reflect a higher prevalence of preexisting cardiorespiratory disease among Maori, or a difference in the toxicity of air pollution to which different ethnic groups are typically exposed. Alternatively, this finding may reflect biases in exposure estimates. We found no other suggestion of interaction of social factors with $\mathrm{PM}_{10}$ in the association with mortality.

\section{CONCLUSION}

In this longitudinal study we report an association of $\mathrm{PM}_{10}$ with mortality, consistent with that reported elsewhere, in a country with low levels of air pollution. The major limitation of our study is the probable misclassification of the $\mathrm{PM}_{10}$ exposure. On balance, this means we have probably underestimated the strength of association. The study design has several strengths, including national population coverage and good control of confounding. We found that the association was, as hypothesised a priori, stronger for cardiorespiratory deaths and people with less residential mobility.

\section{What is already known on this subject}

Relatively few cohort studies of the health effects of urban air pollution have been published, particularly outside north America and Europe. We report here findings from a longitudinal study in New Zealand, based on the national census. There is evidence, most consistently in studies with individual measurement of social factors, that more deprived populations are particularly sensitive to air pollution effects.

\section{What this study adds}

We found an association of $\mathrm{PM}_{10}$ with mortality in a country with relatively low levels of air pollution. There was some evidence that Maori may have greater susceptibility to life-shortening effects of air pollution. This might reflect a higher prevalence of pre-existing cardiorespiratory disease among Maori. 
Acknowledgements The authors would like to thank June Atkinson for preparing the data for analysis.

Funding The study was funded by the National Institute of Water and Atmospheric Research (NIWA). The New Zealand Census Mortality Study is conducted in collaboration with Statistics New Zealand and within the confines of the Statistics Act 1975. The New Zealand Census Mortality Study study was funded by the Health Research Council of New Zealand, and receives continuing funding from the Ministry of Health. The funders had no role in study design, data collection and analysis, decision to publish, or preparation of the manuscript.

Competing interests None.

Contributors TB conceived the analysis and contributed to the design, interpretation and revision of drafts. SH performed the analyses, drafted the text of the paper and contributed to the design and interpretation of results. SH had full access to the data, and takes responsibility for the integrity of the analysis and the accuracy of the results. AW contributed to study design, the interpretation of results and revision of drafts.

Provenance and peer review Not commissioned; externally peer reviewed.

\section{REFERENCES}

1. Cohen AJ, Anderson HR, Ostro B, et al. The global burden of disease due to outdoor air pollution. J Toxicol Environ Health A 2005:68:1301-7.

2. McMichael AJ, Anderson HR, Brunekreef $B$, et al. Inappropriate use of daily mortality analyses to estimate longer-term mortality effects of air pollution. Int $J$ Epidemiol 1998:27:450-3.

3. Dockery DW, Pope CA, Xu X, et al. An association between air pollution and mortality in six U.S. cities. N Engl J Med 1993;329:1753-9.

4. Pope CA, Thun MJ, Namboodiri MM, et al. Particulate air pollution as a predictor of mortality in a prospective study of U.S. adults. Am J Respir Crit Care Med 1995:151:669-74.

5. Krewski D, Burnett R, Goldberg M. Reanalysis of the Harvard six cities study and the American cancer society study of particulate air pollution and mortality. Cambridge, MA: Health Effects Institute, 2000.

6. Pope CA, Burnett RT, Thun MJ, et al. Lung cancer, cardiopulmonary mortality, and long-term exposure to fine particulate air pollution. JAMA 2002;287:1132-41.

7. Filleul L, Rondeau V, Vandentorren $S$, et al. Twenty five year mortality and air pollution: results from the French PAARC survey. Occup Environ Med 2005;62:453-60.

8. Gehring U, Heinrich J, Krämer U, et al. Long-term exposure to ambient air pollution and cardiopulmonary mortality in women. Epidemiology 2006;17:545-51.

9. Laden F, Schwartz J, Speizer FE, et al. Reduction in fine particulate air pollution and mortality: extended follow-up of the Harvard Six Cities study. Am J Respir Crit Care Med 2006; 173:667-72.

10. Elliott $\mathbf{P}$, Shaddick G, Wakefield JC, et al. Long-term associations of outdoor air pollution with mortality in Great Britain. Thorax 2007;62:1088-94.
11. Laurent O, Bard D, Filleul $\mathrm{L}$, et al. Effect of socioeconomic status on the relationship between atmospheric pollution and mortality. J Epidemiol Community Health 2007:61:665-75

12. Naess 0, Piro FN, Nafstad P, et al. Air pollution, social deprivation, and mortality a multilevel cohort study. Epidemiology 2007;18:686-94.

13. Beelen R, Hoek G, van Den Brandt PA, et al. Long-term effects of traffic-related air pollution on mortality in a Dutch cohort (NLCS-AIR study). Environ Health Perspect 2008;116:196-202.

14. Puett RC, Schwartz J, Hart JE, et al. Chronic particulate exposure, mortality, and coronary heart disease in the Nurses' Health Study. Am J Epidemiol 2008; 168:1161-8.

15. Zeger SL, Dominici F, McDermott A, et al. Mortality in the medicare population and chronic exposure to fine particulate air pollution in urban centers (2000-2005). Environ Health Perspect 2008;116:1614-19.

16. Jerrett M, Finkelstein MM, Brook JR, et al. A cohort study of traffic-related air pollution and mortality in Toronto, Ontario, Canada. Environ Health Perspect 2009:117:772-7.

17. Krewski D, Jerrett M, Burnett R, et al. Extended follow-up and spatial analysis of the American Cancer Society study linking particulate air pollution and mortality. Boston MA: Health Effects Institute, 2009.

18. Yorifuji T, Kashima S, Tsuda T, et al. Long-term exposure to traffic-related air pollution and mortality in Shizuoka, Japan. Occup Environ Med 2010;67:111-17.

19. Blakely T, Salmond C, Woodward A. Anonymous linkage of New Zealand mortality and census data. Aust NZ J Public Health 2000;24:92-5.

20. Hill S, Atkinson J, Blakely T. Anonymous record linkage of census and mortality records 1981, 1986, 1991, 1996 census cohorts. Wellington: University of Otago, 2002.

21. Fawcett J, Blakely T, Atkinson J. Weighting the 81, 86, 91 \& 96 census-mortality cohorts to adjust for linkage bias. Wellington: University of Otago, 2002.

22. Kingham S, Fisher G, Hales $\mathrm{S}$, et al. An empirical model for estimating census unit population exposure in areas lacking quality monitoring. J Expo Sci Environ Epidemio 2007; 18:200-10.

23. Zawar-Reza P, Kingham S, Pearce J. Evaluation of a year-long dispersion modelling of $\mathrm{PM}^{10}$ using the mesoscale model TAPM for Christchurch, New Zealand. Sci Total Environ 2005:349:249-59.

24. Blakely T, Fawcett J, Hunt D, et al. What is the contribution of smoking and socioeconomic position to ethnic inequalities in mortality in New Zealand? Lancet 2006;368:44-52.

25. Salmond C, Crampton P. NZDep96: what does it measure? Soc Policy J NZ 2001:17:82-100.

26. Leathwick J, Wilson G, Stephens R. Climate surfaces for New Zealand. Hamilton: Landcare, 2002.

27. Puett RC, Hart JE, Yanosky JD, et al. Chronic fine and coarse particulate exposure, mortality, and coronary heart disease in the Nurses' Health Study. Environ Health Perspect 2009;117:1697-701.

28. Deguen S, Zmirou-Navier D. Social inequalities resulting from health risks related to ambient air quality -a European review. Eur J Public Health 2010;20:27-35.

29. Pelucchi C, Negri E, Gallus $S$, et al. Long-term particulate matter exposure and mortality: a review of European epidemiological studies. BMC Public Health 2009;9:8. 